Pecvnia, Monográfico (2008), pp. 33-64

\title{
La difusión de las prácticas de responsabilidad social en las empresas multinacionales
}

Este artículo se centra en el estudio de la dimensión internacional de la responsabilidad social corporativa (RSC). Se estudia el proceso de difusión que han experimentado las prácticas de RSC en el plano internacional, se identifican distintas concepciones de RSC y se analizan sus efectos sobre la eficiencia. Adicionalmente, se analizan los problemas específicos que plantea a las empresas multinacionales la adopción de criterios socialmente responsables.

Palabras clave: Responsabilidad Social Corporativa (RSC), Empresas Multinacionales, Grupos de interés.

\author{
Mariano Nieto Antolín \\ mariano.nieto@unileon.es \\ Universidad de León \\ Organización de Empresas \\ Fac. de Ciencias Económicas y Empresariales \\ Campus de Vegazana, $\mathrm{s} / \mathrm{n}$ \\ 24071 León (España)
}

This article focuses on the international dimension of Corporate Social Responsibility (CSR). The diffusion process of CSR practices in an international context is studied, and different views of CSR are identified. Moreover, this paper analyzes how CSR practices affect firm's efficiency and it also explores the specific problems multinational companies face when adopting socially responsible criteria.

Key words: Corporate Social Responsibility (CSR), Multinational Enterprises (MNEs), Stakeholders. 


\section{INTRODUCCIÓN}

El gobierno corporativo en las empresas multinacionales (MNEs) y la consideración de la dimensión social y medioambiental de sus actividades ha adquirido una importancia notable en los últimos años. A pesar de que hay evidencia de los efectos positivos que inducen las MNEs en los países donde se instalan -estimulan el crecimiento económico y el desarrollo social, aumentan la cantidad y la calidad del empleo, facilitan la transferencia de nuevos conocimientos y tecnologías, intensifican la competencia, etc.-, con frecuencia su legitimidad es cuestionada por algunos sectores sociales. Tradicionalmente se acusa a las MNEs de desplazar a las empresas locales, emplear tecnologías que no siempre se adaptan a las características de los entornos de los países de destino, crear puestos de trabajo no cualificados con bajos salarios, contribuir a la llamada McDonalización de la sociedad, manipular los precios de transferencia para reducir los impuestos locales y abusar de su poder político y económico en los países de acogida (Kolk et al. 2006).

La imagen negativa que algunos grupos de interés perciben del conjunto de empresas multinacionales se ve reforzada cuando alguna de ellas realiza malas prácticas medioambientales o actúa de forma socialmente irresponsable. Por ejemplo, la mala gestión realizada por algunas MNEs -como Exxon o Union Carbide-Dow Chemical- de los accidentes en los que se han visto implicadas ha provocado catástrofes medioambientales -Exxon-Valdez, Bhopal- a cuyo recuerdo, difícil de borrar, su imagen siempre quedará vinculada. El impacto y la notoriedad de los comportamientos socialmente irresponsables de otras como Nestlé (caso de las leches maternizadas), Nike (empleo de mano de obra infantil) o Merck (caso Vioxx) han generado desconfianza y supuesto importantes pérdidas, no sólo para las empresas directamente implicadas, sino para toda la industria. Los últimos escándalos corporativos protagonizados por grandes empresas como Enron, Parmalt, o WorldCom han deteriorado la imagen de las MNEs ante amplios sectores sociales y han erosionado su legitimidad. Como ha señalado el premio Nobel de economía Joseph Stiglitz "para muchas personas las corporaciones multinacionales vienen a simbolizar los males de la globalización y otros dirían que son las principales causantes de sus problemas" (Stiglitz 2006: 241).

Para contrarrestar estos efectos en los últimos años las MNEs se han replanteado las relaciones que mantienen con los principales grupos sociales en los entornos en los que desarrollan sus actividades. Los directivos de las MNEs, además de atender a los intereses de los accionistas 
(shareholders), han comenzado a tener en cuenta y a satisfacer las expectativas de otros grupos de interés (stakeholders), como los formados por los empleados, clientes, proveedores, administraciones públicas, inversores, miembros de la comunidad local y algunas influyentes ONGs. Así, para satisfacer las expectativas de los grupos preocupados por el medioambiente, numerosas empresas han puesto en marcha programas de eficiencia energética para reducir las emisiones de $\mathrm{CO}_{2} \mathrm{O}$ han diseñado sistemas logísticos de retorno para reciclar sus productos cuando éstos finalizan su ciclo de vida. En respuesta a la creciente demanda de productos éticos y ecológicos en algunos mercados, como el alimentario o el textil, las empresas han incorporado atributos medioambientales y sociales en sus productos y procesos. En la industria farmacéutica y cosmética se han limitado las pruebas con animales como consecuencia de las exigencias de los colectivos preocupados por su bienestar. Para reforzar su legitimidad ante las comunidades locales las empresas promueven una gran variedad de acciones sociales, culturales, educativas, sanitarias, etc. Todas estas iniciativas y otras muchas constituyen lo que en la actualidad se conoce como Responsabilidad Social Corporativa (RSC).

\section{EL CONCEPTO DE RSC}

La RSC engloba un conjunto heterogéneo de políticas y acciones que promueven las empresas de forma voluntaria con el objetivo de satisfacer las expectativas de los grupos de interés (Bondy et al. 2008). Desde una perspectiva económica, la RSC puede entenderse como el compromiso que asumen las empresas de contrarrestar el efecto de las externalidades negativas (p.e. contaminación medioambiental) que generan sus actividades. En este sentido la RSC refleja la percepción que tienen los directivos de los efectos sociales y medioambientales de las actividades que realizan sus empresas y las restricciones que se imponen voluntariamente para amortiguarlas (Sethi 1990).

El concepto de responsabilidad social corporativa o RSC (Corporate Social Responsibility o CSR) se solapa y compite con otros conceptos y términos como los de responsabilidad social de la empresa o RSE, ética empresarial (business ethics), ciudadanía empresarial (corporate citizenship), empresa sostenible (corporate sustainability), filantropía empresarial (corporate philanthropy), transparencia y rendición de cuentas (corporate accountability), environmental, social and governance issues $(E S G)$ y otros muchos que se emplean igualmente para hacer referencia a 
los compromisos sociales y medioambientales que las empresas asumen con la sociedad.

Actualmente coexisten numerosas $\mathrm{y}$, en apariencia, contradictorias interpretaciones de lo que representa la RSC. Sin embargo, en la mayor parte de ellas subyacen tres aspectos relevantes (Nieto 2005):

- La RSC es de carácter voluntario. Esto significa que cuando las empresas informan de sus políticas y acciones de RSC están comunicando a los grupos de interés que voluntariamente han decidido ajustar su comportamiento no sólo a lo establecido por los preceptos legales y los principios económicos, sino también a las normas, valores y expectativas sociales que predominan en su entorno.

- La RSC implica modificar el proceso de toma de decisiones al añadir a los criterios de eficiencia económica la consideración del impacto ambiental y social de las actividades de la empresa.

- La RSC supone modificar el diseño tradicional de la estructura de gobierno corporativo de la empresa. Se pasa de una relación bilateral entre accionistas y directivos (enfoque shareholders) a otra multilateral en la que participan todos los grupos de interés, que incluye accionistas, directivos, empleados, clientes, proveedores, administraciones publicas, inversores y comunidad local (enfoque stakeholders).

La incorporación de criterios de RSC en el gobierno y la dirección de las empresas no es una tarea fácil ya que requiere desarrollar procesos y estructuras que permitan controlar los costes de agencia entre la dirección y los grupos de interés (Luo 2005). No obstante, el número de empresas que ha decidido adoptar principios de RSC crece sin cesar. De esta forma persiguen reforzar su legitimidad y aumentar la credibilidad de sus decisiones e informes.

Las compañías más reputadas internacionalmente han sido las primeras en informar, a través de informes corporativos, del impacto que sus actividades tienen sobre los principales grupos de interés y en comunicar las iniciativas que emprenden para mejorar su entorno social y el medioambiente. En el Cuadro 1 se recogen datos que muestran cómo ha aumentado el porcentaje de MNEs que elabora informes de sostenibilidad. 


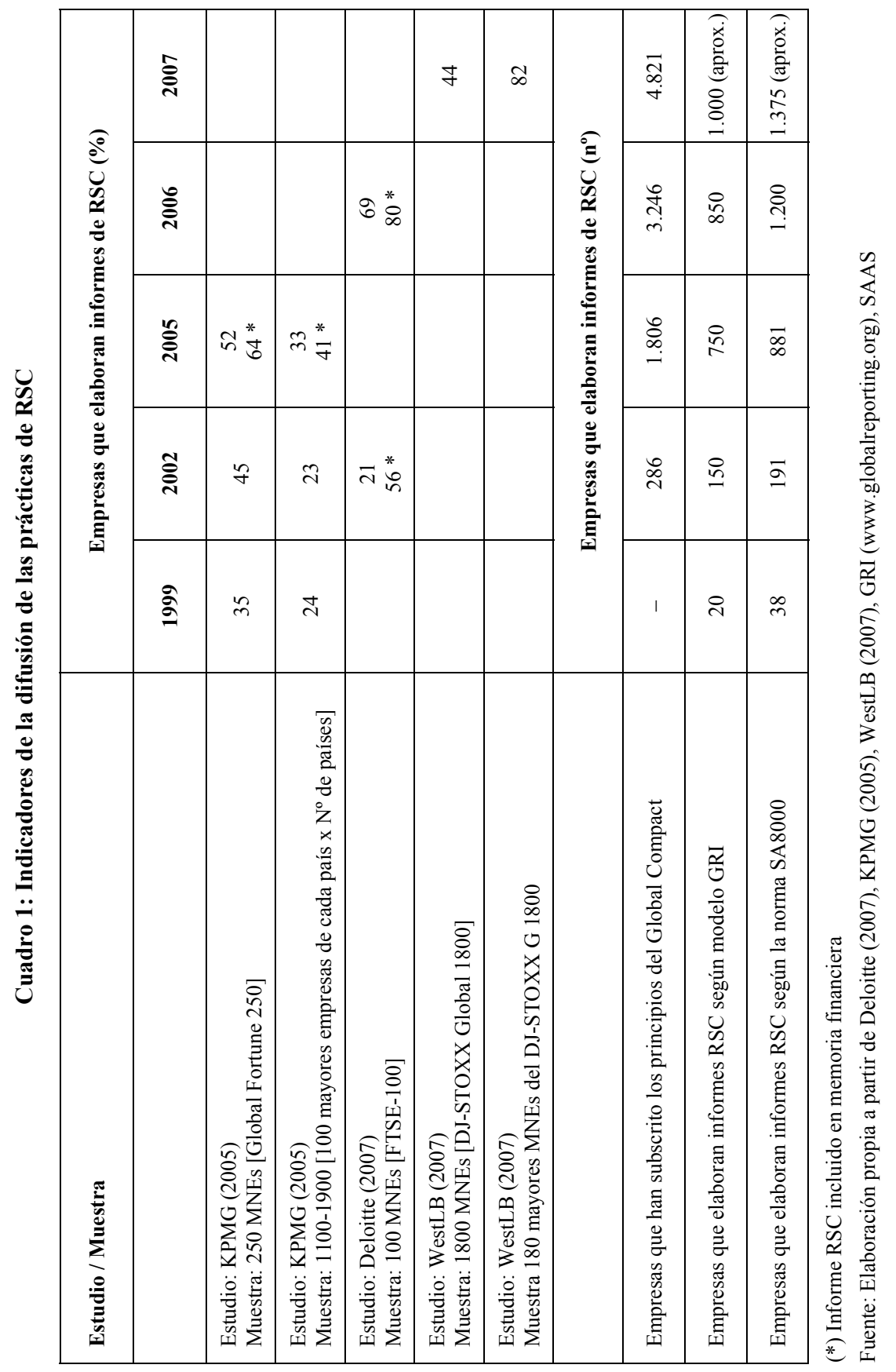

Pecvnia, Monográfico (2008), pp. 33-64 
El estudio realizado por KPMG en 2005 indica que más de la mitad (52\%) de las 250 mayores MNEs recogidas en el Global Fortune 250 presentaba informes sobre sus actividades de RSC. Estos porcentajes son similares a los que ofrecen otros estudios recientes realizados por las consultoras WestLB (2007), sobre las 1.800 empresas listadas en el Dow Jones Stoxx Global 1800 y Deloitte, sobre las 100 mayores empresas de Reino Unido incluidas en el índice FTSE-100.

Estos datos indican que las iniciativas en el ámbito de la RSC se han intensificado en los últimos años, lo que supone un cambio importante en los principios que orientan la estrategia y el gobierno de las empresas. Si esta tendencia se mantiene y no pasa de moda, como ha ocurrido con otros enfoques en la dirección de empresas, probablemente estemos asistiendo al comienzo de una nueva etapa en el desarrollo económico, caracterizada por que las empresas han comenzado a asumir nuevas responsabilidades sociales y medioambientales más allá de su responsabilidad económica fundamental.

\section{DIFERENTES VISIONES DE LOS EFECTOS DE LA RSC}

La trascendencia de los comportamientos socialmente responsables ha reabierto el viejo debate sobre la conveniencia de que las empresas asuman compromisos más allá de los establecidos por las leyes y la racionalidad económica.

\subsection{La RSC como fuente de ineficiencias}

Tradicionalmente se ha señalado que adoptar criterios de RSC para satisfacer los objetivos de grupos de interés distintos de los accionistas va en contra de los principios de racionalidad económica y genera ineficiencias. Miltom Friedman resume este argumento en un célebre artículo publicado en The New York Times Magazine el 13 de septiembre de 1970 bajo el expresivo título "The Social Responsibility of Business is to Increase its Profits". En este trabajo califica a la RSC como una doctrina subversiva y enfatiza que la única responsabilidad que tienen los directivos en una economía de mercado es emplear los recursos de sus empresas en aumentar los beneficios de los accionistas en el marco de la ley.

En la actualidad, numerosos académicos siguen cuestionando la eficiencia económica y social de las prácticas de RSC. Argumentan que 
adoptar criterios de RSC para satisfacer los objetivos de grupos de interés distintos de los accionistas destruye valor y genera ineficiencias por varios motivos (Jensen 2001):

- Atender las demandas de todos los grupos de interés supondría hacerles partícipes de una redistribución de los beneficios que perjudicaría a los accionistas destruyendo valor. El enfoque stakeholder que subyace en la RSC pone en manos de los grupos de interés con mayor poder el control de los recursos de la empresa los cuales, probablemente, los asignarían discrecionalmente para satisfacer sus propios fines.

- Las prácticas de RSC pueden ser instrumentalizadas por los directivos para evitar el control por parte de los accionistas. Por ello, se ha señalado que la RSC puede resultar atractiva para los directivos ya que permite ocultar los comportamientos oportunistas.

- Adoptar voluntariamente criterios sociales o medioambientales por encima de lo establecido por la ley conlleva añadir restricciones que provocarían una asignación ineficiente de los recursos.

- La RSC también ha sido cuestionada por razones de tipo operativo. En este sentido, la objeción mas seria que han recibido las teorías que justifican los comportamientos socialmente responsables se fundamenta en la imposibilidad de maximizar simultáneamente más de una función objetivo.

- Adicionalmente se ha señalado que los directivos están especialmente capacitados para adoptar decisiones en el ámbito económico (financieras, comerciales o productivas) y no tienen por que disponer de las habilidades necesarias para adoptar decisiones sociales.

- También hay que tener en cuenta que cuando los directivos dedican esfuerzos a tratar problemas RSC pueden desviar su atención de las actividades centrales de sus negocios.

- Por ultimo, se ha señalado que el enfoque de RSC no está respaldado por una teoría sólida sino que es más bien es conjunto de ideas bien intencionadas pero disparatadas y por ello tampoco, cuenta con un conjunto coherente de prácticas (Baron 2001).

Según estos argumentos la difusión de las prácticas de RSC entre las empresas generalizaría las ineficiencias y, paradójicamente, 
conduciría a un resultado contrario al buscado inicialmente: la disminución del bienestar social (Jensen 2001).

\subsection{La incorporación de la RSC en la estrategia empresarial}

La mayoría de estas críticas reflejan el problema de encajar los comportamientos cooperativos y altruistas típicos de la RSC en la lógica individualista que subyace en los supuestos de racionalidad de los modelos económicos tradicionales (Ghoshal 2005). Sin embargo, un creciente número de autores ha señalado en los últimos años que la RSC no tiene por qué ser incompatible con la racionalidad económica y la creación de valor. Esta idea está respaldada por abundante evidencia empírica que ha verificado la existencia de una relación positiva entre RSC y rentabilidad financiera (Fernández 2005). Después de revisar todas las investigaciones realizadas desde 1972, Margolis y Walsh (2003), han encontrado que en la mayoría de ellas se observa una correlación positiva entre rendimiento social (social performance) y financiero (financial performance). Asimismo, un meta-análisis llevado a cabo por Orlitzky et al. (2003) y que ha tenido en cuenta las 52 investigaciones más relevantes realizadas hasta la fecha, llega a la misma conclusión. Adicionalmente, en este trabajo se comprueba que la relación entre rendimiento social y financiero es bidireccional y simultánea.

Los principios de RSC constituyen, más que un conjunto de obligaciones, una fuente de oportunidades estratégicas que pueden evaluarse de la misma manera que otras inversiones empresariales (Davis 2005). Desde esta perspectiva los directivos actúan como agentes racionales cuando promueven iniciativas de RSC y si deciden invertir en RSC es porque consideran que es la mejor opción para la asignación de los recursos disponibles y sólo adoptarán la decisión cuando el valor actual de los rendimientos esperados compense el coste de la inversión (incluido el de oportunidad). Si las expectativas son correctas, la inversión en RSC puede ser tan rentable como cualquier otra. De acuerdo con este planteamiento la RSC es la prestación privada de un bien público y las empresas socialmente responsables son las que vinculan su contribución social a la obtención de algún rendimiento (aumento de ventas de productos, mejora de la reputación, etc.).

Las iniciativas de RSC pueden reportar beneficios a las empresas y crear valor por los tres motivos siguientes: (a) previenen la aparición de amenazas ya que facilitan el control de los riesgos sociales y 
ambientales, (b) permiten explotar nuevas oportunidades y fuentes de ventaja competitiva en el ámbito social y medioambiental, (c) mejoran la eficiencia de la empresa reduciendo los costes de transacción.

\subsubsection{Control de riesgos sociales y medioambientales}

La incorporación de criterios de RSC en el gobierno de las empresas supone la puesta en marcha de procesos para identificar, evaluar y controlar las expectativas de los grupos de interés. Las iniciativas de RSC permiten alcanzar, a partir de los recursos disponibles, un grado aceptable de adecuación entre las acciones de las empresas y las expectativas de sus grupos de interés. De esta forma se amortiguan los conflictos y se elimina la amenaza de posibles acciones que puedan emprender en contra de las empresas los grupos que consideren que éstas tienen comportamientos socialmente irresponsables. En este sentido se ha comprobado que los comportamientos socialmente responsables (Baron 2001; Lyon y Maxwell 2006; Maxwell et al. 2000): (a) contribuyen a reducir riesgos en la medida que reducen la amenaza de regulación, (b) previenen presiones procedentes de otras empresas de la misma industria o asociaciones industriales, (c) evitan reacciones negativas de la opinión pública y de las asociaciones de consumidores, (d) eluden la atención de los activistas y de las ONGs y (e) eliminan la posibilidad de posibles boicots por parte de los consumidores.

Al controlar los riesgos sociales y medioambientales de las empresas, la RSC contribuye indirectamente a reducir otros costes. La formalización de las prácticas de RSC indica que las empresas tienen establecidos sistemas de control interno rigurosos, los cuales constituyen una garantía para las entidades financieras -reducen el coste de financiación- y para las empresas aseguradoras -reducen las primas-. También, los códigos de conducta y los procedimientos internos derivados de la aplicación de los principios de RSC pueden proporcionar argumentos para la defensa de la empresa en el supuesto de que deba hacer frente a demandas legales por eventuales comportamientos negligentes y reducir, en su caso, el importe de las sanciones.

\subsubsection{Explotación de oportunidades}

Por otro lado, la RSC representa una opción estratégica que permite explotar las fuentes de ventaja competitiva en el ámbito social y medioambiental. Las prácticas de RSC pueden contribuir a reforzar la 
estrategia de la empresa para conseguir y mantener una posición de ventaja competitiva (Barón 2001; McWilliams y Siegel 2001). En muchos casos las iniciativas de RSC pueden ser instrumentos adecuados para: (a) obtener contratos con empresas o gobiernos, (b) crear barreras de entrada a la industria, (c) facilitar el acceso a nuevos mercados, (d) diferenciarse de los competidores y (e) atraer a inversores y consumidores socialmente responsables (Bagnoli y Watts 2003).

También las prácticas de RSC facilitan la acumulación de activos intangibles y refuerzan la reputación de las empresas ya que transmiten a los grupos de interés una imagen positiva de responsabilidad y de compromiso con sus expectativas. Por ejemplo, las empresas que ofertan productos socialmente responsables refuerzan su imagen ante la sociedad, mostrando que sus actividades productivas se realizan bajo estrictos criterios éticos y socialmente aceptables y que son medioambientalmente sostenibles. De esta forma comunican a sus grupos de interés que se son conscientes del impacto de las externalidades negativas que generan sus actividades y que se esfuerzan en reducirlas. En general, las empresas socialmente responsables mantienen mejores relaciones no sólo con sus clientes, sino con el conjunto de la sociedad.

Las prácticas de RSC, también, pueden ayudar a reforzar los recursos internos de las empresas y mejorar la calidad del contexto competitivo en el que operan. Se ha reconocido que las empresas que orientan las prácticas de RSC hacia sus empleados mejoran el clima laboral, reducen el absentismo y los costes derivados de los conflictos laborales. Estas empresas resultan más atractivas ante sus empleados $\mathrm{y}$, por ello, tienen una capacidad superior para atraer y conservar los recursos humanos más competentes. Adicionalmente, las prácticas de responsabilidad con proveedores, clientes y la comunidad local inciden directamente sobre aspectos clave del contexto competitivo de las empresas ya que mejoran la oferta de inputs especializados de alta calidad, potencian una demanda sofisticada y exigente, crean un entorno más productivo y transparente y mejoran los sectores relacionados y complementarios (Porter y Kramer 2002).

El compromiso social, además, puede ser origen de nuevas oportunidades empresariales en el ámbito de lo social y medioambiental. Las necesidades de lo que Prahalad (2005) ha denominado Base de la Pirámide BOP -es decir, la población mundial que cuenta con menores recursos y que habita en las regiones más pobres del planeta-, constituye una fuente inagotable de oportunidades. Se ha señalado que, explotando 
este mercado potencial de enormes dimensiones, las MNEs pueden reforzar su propia prosperidad al tiempo que contribuyen a reducir la pobreza y el desarrollo económico de estos países.

\subsubsection{Mejora de la eficiencia}

La RSC permite a las empresas definir un marco estable de relaciones con sus grupos de interés, un marco que genera confianza, crea capital social, reduce los costes de transacción y mejora la eficiencia. Los principios que orientan las prácticas de RSC sirven para formalizar los compromisos de las empresas con la sociedad, transmiten credibilidad y refuerzan su legitimidad frente a los stakeholders. En cierta medida, las empresas obtienen, a través de ellos, la "licencia de la sociedad" para operar. Con los informes de RSC las empresas rinden cuentas a los principales grupos de interés, -reguladores, consumidores, empleados, acreedores, proveedores y la comunidad local- (Shearer 2002) y les informa de las decisiones estratégicas que pueden afectar significativamente a sus intereses (Luo 2005). La empresa desarrolla sus funciones mas eficientemente cuando todos los stakeholders, que aportan recursos -capital, financiación, conocimientos, trabajo, servicios y entorno- cooperan compatibilizando sus objetivos a largo plazo.

Las prácticas de RSC generan confianza y facilitan la cooperación entre las empresas y la sociedad. Cuando la inversión en RSC se mantiene en el tiempo, la confianza se acumula creando un depósito de capital de carácter social. El capital social es un activo que refleja el grado de confianza que existe entre la empresa y los grupos sociales. Los entornos que gozan de un nivel elevado de capital social facilitan las relaciones económicas de la empresa con sus grupos de interés, estimulan la cooperación y tienen un elevado potencial para crear valor (Putnam 2003). La confianza hace que las relaciones de la empresa con sus grupos de interés sean más fluidas. Cuando estas relaciones son a largo plazo (relaciones laborales, contratos de aprovisionamiento con subcontratistas, adquisición de bienes de consumo duradero, operaciones de crédito, etc.), la confianza reduce el riesgo de comportamientos oportunistas y por lo tanto disminuye los costes de transacción y supervisión (Williamson 1993).

Los incentivos para invertir en RSC serán elevados en entornos donde la confianza que genera el capital social pueda tener un mayor efecto reductor sobre los costes de transacción (Spence 2002). Es 
el caso de industrias donde hay asimetrías de información y el riesgo asociado a las transacciones es elevado, como en la industria farmacéutica, el sector financiero, el mercado de trabajo, etc.

Los criterios y principios de RSC que asumen las empresas permiten canalizar las expectativas y regular los comportamientos de los grupos de interés externos e internos haciéndolos compatibles con los intereses de la dirección. Los estándares éticos que subyacen en los principios de RSC no sólo obligan a la empresa, sino que también vinculan a todos los interesados. Los códigos en los que se formalizan los criterios y principios de RSC comprometen personalmente a todos los empleados y directivos, especialmente si se incluyen como un elemento más dentro del contrato de trabajo, y protegen a la empresa de eventuales comportamientos deshonestos.

En este sentido, estudios realizados recientemente han puesto de manifiesto que las prácticas organizativas que se derivan de aplicar los principales códigos de conducta sobre RSC mejoran la eficiencia de las MNEs. Permiten alcanzar el doble objetivo de cumplir con los principios establecidos en los códigos y, a la vez, proteger los activos de la empresa. El cumplimiento de las recomendaciones establecidas en códigos de RSC -como UN 2000 Global compact; ILO 1977 Tripartite Declaration of Principles concerning Multinational Enterprises and Social Policy; ILO 1998 Declaration on Fundamental Principles and Rights at Work, entre otros- refuerza la disciplina interna de la organización y mejora las relaciones con los grupos de interés (Béthoux et al. 2007).

\subsection{La instrumentalización de la RSC}

También se ha cuestionado la RSC desde una postura muy diferente a la de la racionalidad económica mencionada anteriormente, criticando la instrumentalización que hacen las MNEs de sus prácticas. Algunos autores ponen en duda que la RSC tenga una motivación altruista (Matten y Moon 2008) y enfatizan el carácter oportunista de alguna de las iniciativas como, por ejemplo, el Responsable Care Program puesto en marcha por la industria química (King y Lenox 2000). Se ha señalado que, una vez que son adoptados e implementados, los códigos de RSC se transforman en una herramienta más de gestión puesta al servicio de los intereses de la dirección. Fundamentalmente se critica que las prácticas de RSC se dirijan a comprometer -y de hecho a forzar- a los grupos de interés con el cumplimiento de los objetivos de la organización y se 
afirma que la subordinación de la RSC a los intereses de la dirección de la empresas es un reflejo del proceso de "amoralización" de las cuestiones éticas en las organizaciones (Crane 2000).

Al aflorar conflictos de intereses entre los gobiernos nacionales y las MNEs, la globalización y la internacionalización de las actividades de la cadena de valor en la mayoría de las industrias han favorecido la instrumentalización de las prácticas de RSC. Se ha señalado que, en la actualidad, las MNEs operan en un entorno que se caracteriza por un vacío moral y legal en el que ellas mismas deben definir los límites de sus propios comportamientos. (Gond et al. 2007). Tampoco se cuenta con legislación aplicable internacionalmente, ni con instituciones que controlen el cumplimiento de las normas, ni existen mecanismos sancionadores. En este contexto, la autorregulación del comportamiento de las MNEs mediante la aplicación voluntaria de códigos RSC, sin control externo, puede que no contribuya a corregir las ineficiencias sociales.

\section{LAS PRÁCTICAS DE RSC EN LAS MNES}

Las dificultades que plantea la incorporación de criterios de RSC en el gobierno corporativo de cualquier empresa se amplifican en el caso de las MNEs. Debido a su naturaleza, el diseño e implementación de las estrategias de RSC en las MNEs plantea dos problemas específicos que no tienen las empresas nacionales: (a) ¿cómo identificar y evaluar las expectativas de numerosos y diversos grupos de interés? y (b) ¿cómo equilibrar la adaptación local y la coordinación global de las actividades de RSC?

\subsection{Diversidad de grupos de interés}

Las MNEs están constituidas por una compleja de red de unidades organizativas dispersas en numerosos países (subsidiarias) coordinadas desde una unidad localizada en el país de origen (oficina central). El hecho de que las MNEs desarrollen sus actividades en países con entornos institucionales muy diferentes obliga a tener en cuenta numerosos y heterogéneos grupos de interés. Por un lado, deben tener en cuenta a todos los grupos de interés locales, tanto los más próximos a la oficina central (accionistas, empleados, consumidores, proveedores, comunidad local y el medio ambiente), como los de las subsidiarias de 
todos los países. También deben considerar a los grupos de interés que operan globalmente, como las instituciones supranacionales (Naciones Unidas, OECD, Comisión Europea, etc.), ONGs de proyección internacional, el medioambiente global y las comunidades locales en los países en vías de desarrollo (conocidos como stakeholders silenciosos).

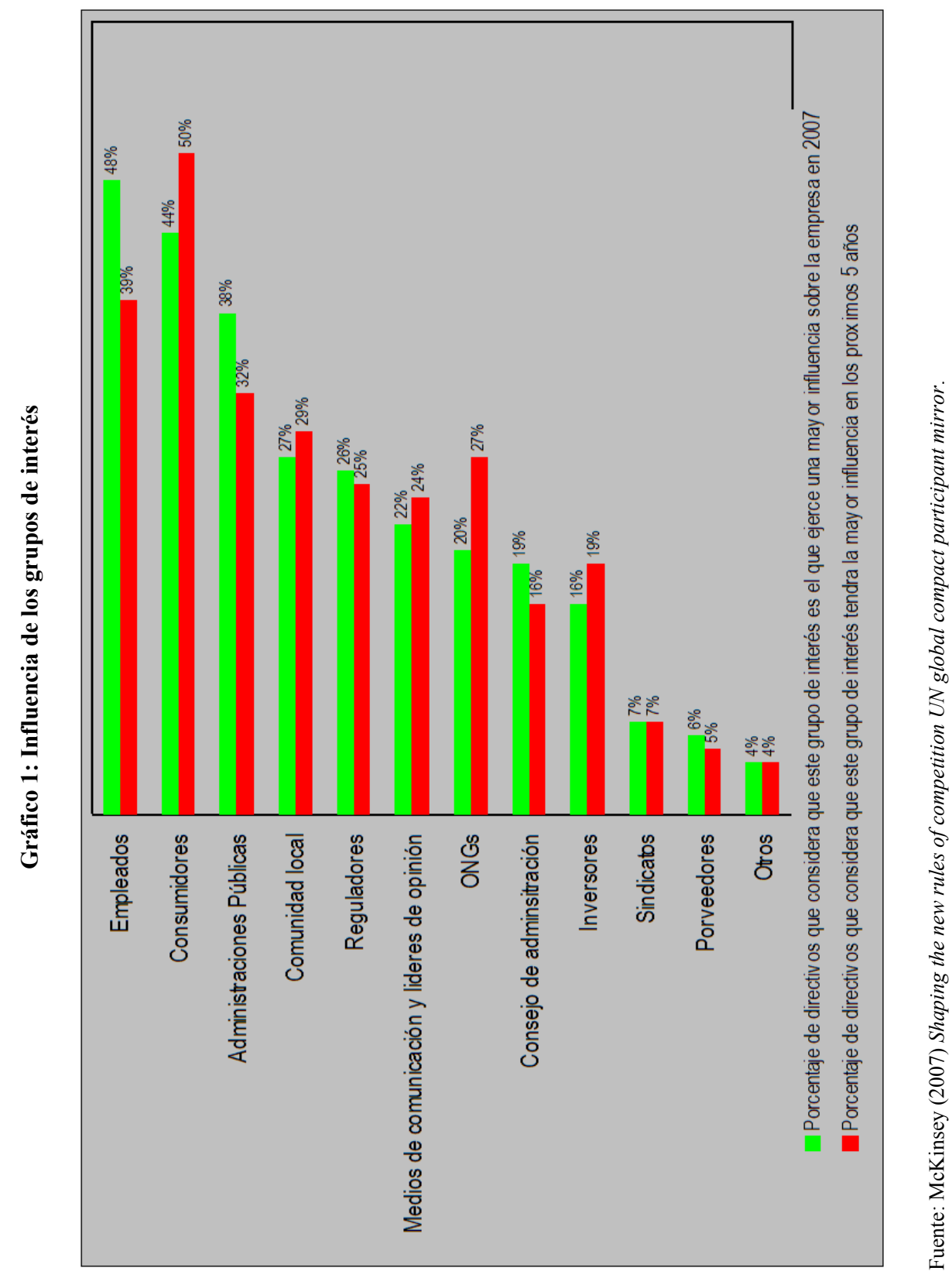


De acuerdo con el informe elaborado por McKinsey en 2007, los empleados y los clientes son los grupos que ejercen una mayor presión sobre las MNEs y, previsiblemente, la influencia de estos últimos aumentará en los próximos cinco años (Gráfico 1). Los valores de la población de los países desarrollados han ido evolucionando hacia posturas menos materialistas, lo que ha modificado las preferencias de los consumidores. El hecho de que la demanda de productos con etiquetas "socialmente responsables" (ecológicos, orgánicos, saludables, naturales, etc.) esté aumentando en estos países a una tasa muy superior a la del resto de productos confirma esta tendencia.

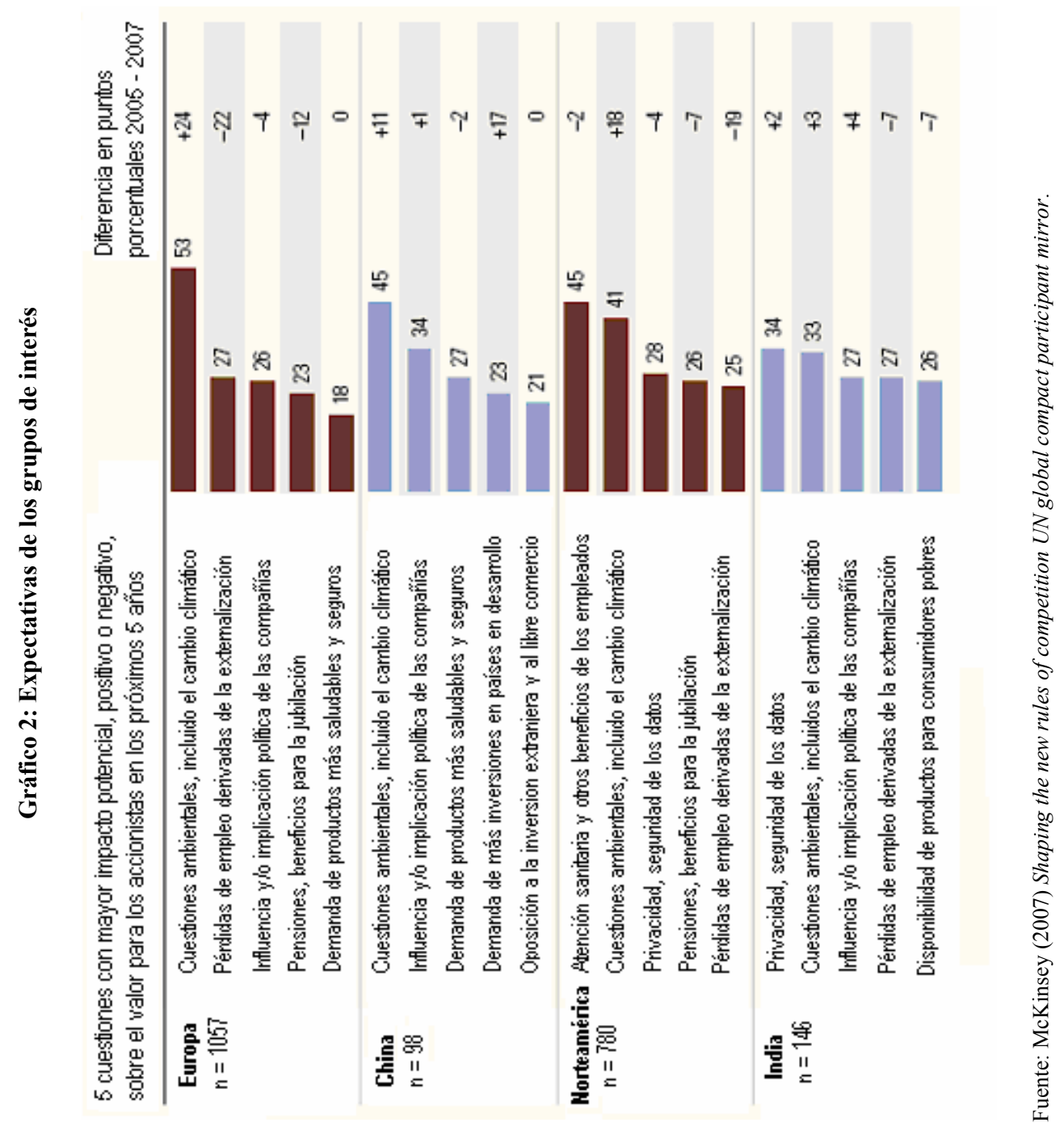


Las MNEs no sólo atienden a un mayor número de grupos de interés, sino que, además, las expectativas de éstos son muy heterogéneas. Las expectativas de los grupos de interés, de la misma forma que los valores y las normas sociales, son diferentes en cada país y varían a lo largo del tiempo. El nivel de desarrollo y el marco institucional -sistema jurídico, nivel de protección social, regulación del mercado de trabajo, legislación medioambiental, valores culturales, etc.- configuran visiones divergentes de los compromisos que deben asumir las empresas con la sociedad (Maignan y Ralston 2002). Por ello las expectativas de los grupos de interés en países que cuentan con una amplia cobertura social no priorizan las prestaciones sociales por parte de la empresa. El Gráfico 2 muestra cómo las valoraciones que hacen los directivos sobre las expectativas de los grupos de interés son diferentes en cada entorno geográfico.

Las MNEs deben considerar que las expectativas de los grupos de interés pueden diferir tanto en el tiempo como en el espacio y, por ello, deben desarrollar iniciativas de RSC adaptadas a las condiciones de cada país y revisarlas periódicamente. Por esta razón, además de la obligación de ajustar los informes financieros a la legislación y las normas contables de cada uno de los países en los que operan, a la hora de elaborar las memorias de RSC las MNEs tienen el problema de procesar una variedad mayor de información.

\subsection{Adaptación local vs. coordinación global}

La estrategia de RSC de las MNEs tiene como principal objetivo legitimar sus actividades en los países en los que operan. La legitimidad es un status que conceden los agentes sociales $y$, por consiguiente, una MNEs se legitimará cuando sus valores y acciones sean congruentes con los valores y las expectativas de los grupos de interés de todos los entornos donde opera. Para dar respuesta a las expectativas de los grupos de interés, las MNEs deben desarrollar iniciativas de RSC adaptadas a las condiciones locales y, a la vez, coordinar todas las actividades de forma que mantengan coherencia interna y refuercen la estrategia de RSC a nivel global. Es decir, deben demostrar lealtad a todos los grupos de interés locales $y$, al mismo tiempo, construir un sistema de valores integrado globalmente. Este problema es similar al dilema central que tienen que resolver las MNEs para llevar a cabo la mayor parte de sus 
actividades: equilibrar la adaptación local (local responsiveness) con la coordinación global (global integration).

La decisión sobre el grado de adaptación de las prácticas de RSC a las condiciones de los entornos locales está condicionada, entre otros, por los siguientes aspectos:

- Aumentar la adaptación local supone flexibilizar los criterios de RSC y, con frecuencia, fijar niveles de cumplimiento de estándares muy bajos, lo que puede tener efectos negativos para la imagen de la empresa y reducir su legitimidad.

- Para adaptar las prácticas de RSC a las exigencias de los entornos locales es necesario que la oficina central delegue en las subsidiarias las tareas de evaluar los grupos de interés locales, decidir qué expectativas atender y diseñar las acciones adecuadas. Esto supone que la oficina central deberá asumir unos mayores costes para procesar la información necesaria para coordinar y controlar las actividades desarrolladas por todas las subsidiarias.

- A medida que aumente la adaptación local de las prácticas de RSC, los costes de agencia que tendrán que asumir los directivos de la oficina central para controlar a los directivos de las subsidiarias aumentarán.

- Cuanto mayor es el grado de adaptación local, más difícil es evaluar los rendimientos de las iniciativas locales de RSC. La independencia estratégica y organizativa con que cada subsidiaria define su estrategia de RSC provoca la aparición de prácticas muy heterogéneas y dificulta establecer criterios que permitan evaluarlas en relación a la estrategia global de RSC.

\section{DIFUSIÓN INTERNACIONAL DE LA RSC}

Numerosas investigaciones han puesto de manifiesto que existen importantes diferencias internacionales en el nivel de desarrollo de la RSC. Estas diferencias vienen determinadas por ciertas características de los entornos institucionales de cada país, como el grado de aceptación de las principios y códigos de RSC propuestos por organismos internacionales, la difusión de buenas prácticas de RSC, la demanda de productos socialmente responsables, el aumento de la inversión socialmente responsable, la elaboración de memorias de RSC por parte de empresas 
reputadas, etc. La mayor parte de estos factores se encuentran recogidos en el Índice de Competitividad Responsable (Responsible Competitiveness Index o $\mathrm{RCl}$ ) propuesto por Accountability para medir el grado en el que el entorno institucional de un país facilita e impulsa las prácticas de la RSC. Este índice se elabora a partir de 21 indicadores agrupados en tres bloques:

- Siete indicadores del impulso político (policy drivers) que reflejan la solidez de políticas públicas de fomento de las prácticas de responsabilidad empresarial: firma de convenios internacionales sobre medio ambiente, ratificación de derechos básicos de los trabajadores, rigidez del índice de empleo, reglamentación estricta sobre medio ambiente, control de emisiones de $\mathrm{CO}_{2}$, empleo femenino y entorno fiscal responsable.

- Siete indicadores de la acción empresarial (business action) que indican el nivel de compromiso de las empresas con las prácticas de buen gobierno corporativo y la responsabilidad social y medioambiental: eficacia de consejo de administración, códigos éticos adoptados, igualdad salarial, solidez de las normas de contabilidad y auditoría, nivel de capacitación de los directivos, certificaciones ISO y accidentes laborales.

- Siete indicadores de la presión social (social enablers) del entorno político y social que impulsan a las empresas hacia las prácticas responsables: índice de percepción de la corrupción, orientación al cliente, libertad de prensa, transparencia en las transacciones, actividad de las ONGs, libertades civiles e impacto de la conservación del aire y del agua sobre las actividades empresariales.

Los países desarrollados, como se refleja en el Cuadro 2 son los que cuentan con un índice de competitividad responsable más elevado. Entre ellos destacan los países europeos ya que, además de ocupar las seis primeras posiciones, dominan los treinta primeros puestos en una relación aproximada de $2 / 3$ (hay 19 entre los 30 primeros), lo que pone de manifiesto que las prácticas de RSC se desarrollan en entornos institucionales de alta calidad. Se ha comprobado que el índice de competitividad responsable $(\mathrm{RCl})$ está correlacionado con otros conocidos indicadores internacionales de la calidad del entorno institucional como el Growth Competitiveness Index, elaborado por el World Economic Forum (con un coeficiente de correlación $R^{2}=0,85$ ) y el Doing Business del Banco Mundial $\left(R^{2}=0,53\right)$. Este hecho corrobora que las prácticas 
responsables son compatibles con elevados niveles de competitividad y que alcanzan un mayor nivel de desarrollo en entornos institucionales favorables a la actividad empresarial (Accountability 2007).

Cuadro 2: Índice de competitividad responsable en 2007

\begin{tabular}{|c|c|c|c|c|c|}
\hline Ranking & País & \begin{tabular}{|c|} 
Índice de \\
Competitividad \\
Responsable \\
(RCI)
\end{tabular} & $\begin{array}{c}\text { Impulso } \\
\text { político }\end{array}$ & $\begin{array}{c}\text { Acción } \\
\text { empresarial }\end{array}$ & $\begin{array}{c}\text { Presión } \\
\text { social }\end{array}$ \\
\hline 1 & Suecia & 81,5 & 86,0 & 90,2 & 74,7 \\
\hline 2 & Dinamarca & 81,0 & 89,9 & 86,9 & 76,6 \\
\hline 3 & Finlandia & 78,8 & 83,9 & 84,1 & 76,7 \\
\hline 4 & Islandia & 76,7 & 83,5 & 74,9 & 86,3 \\
\hline 5 & Reino Unido & 75,8 & 88,8 & 75,9 & 76,6 \\
\hline 6 & Noruega & 75,5 & 83,8 & 77,3 & 75,9 \\
\hline 7 & Nueva Zelanda & 74,9 & 88,6 & 72,2 & 80,0 \\
\hline 8 & Irlanda & 74,6 & 85,0 & 73,8 & 78,1 \\
\hline 9 & Australia & 73,0 & 82,7 & 73,6 & 73,3 \\
\hline 10 & Canadá & 73,0 & 83,7 & 72,5 & 74,8 \\
\hline 11 & Alemania & 72,7 & 81,8 & 74,8 & 70,1 \\
\hline 12 & Holanda & 72,6 & 81,6 & 75,0 & 69,5 \\
\hline 13 & Suiza & 72,5 & 87,8 & 74,5 & 65,7 \\
\hline 14 & Bélgica & 71,9 & 86,1 & 70,1 & 73,0 \\
\hline 15 & Singapur & 71,3 & 83,7 & 74,4 & 63,5 \\
\hline 16 & Austria & 70,9 & 84,1 & 71,6 & 67,2 \\
\hline 17 & Francia & 70,1 & 76,9 & 69,2 & 73,6 \\
\hline 18 & EEUU & 69,6 & 72,6 & 72,1 & 68,6 \\
\hline 19 & Japón & 68,8 & 80,7 & 68,9 & 65,7 \\
\hline 20 & Hong Kong & 68,3 & 84,5 & 68,9 & 60,6 \\
\hline 21 & Portugal & 65,9 & 79,2 & 63,1 & 65,7 \\
\hline 22 & Estonia & 65,0 & 73,5 & 67,4 & 73,0 \\
\hline 23 & Eslovenia & 64,1 & 76,0 & 61,3 & 63,7 \\
\hline 24 & Chile & 64,0 & 80,3 & 65,4 & 67,9 \\
\hline 25 & Malasia & 63,7 & 82,3 & 68,4 & 59,2 \\
\hline 26 & España & 63,7 & 73,3 & 61,4 & 63,3 \\
\hline 27 & Corea & 63,0 & 69,3 & 62,8 & 60,7 \\
\hline$\ldots$ & $\ldots$ & $\ldots$ & $\ldots$ & $\ldots$ & $\ldots$ \\
\hline 105 & Etiopia & 40,8 & 76,4 & 47,2 & 29,9 \\
\hline 106 & Bangladesh & 39,8 & 74,3 & 40,6 & 40,1 \\
\hline 107 & Nepal & 37,5 & 65,1 & 41,0 & 35,8 \\
\hline 108 & Chad & 35,1 & 64,6 & 40,3 & 27,1 \\
\hline
\end{tabular}

Fuente: A. MacGillivray, P. Begley, S. Zadek, Eds. (2007) The State of Responsible Competitiveness 2007. AccountAbility, Londres [www.accountability21.net]. 


\subsection{Las MNEs socialmente responsables}

Si las características del entorno institucional influyen en la difusión de las prácticas de RSC, es previsible que las empresas que operen en países con índices de competitividad responsable elevados tengan una mayor propensión a los comportamientos socialmente responsables. Por ello, la mayoría de los informes coinciden en señalar que las empresas europeas son más activas que las estadounidenses y las japonesas en la práctica de la RSC.

Cuadro 3: Las MNEs con mayor índice de RSC en 2007

\begin{tabular}{|c|c|c|c|c|c|c|c|c|}
\hline Ranking & Empresas & $\begin{array}{c}\text { Ranking } \\
\text { Global } \\
\text { Fortune }\end{array}$ & $\begin{array}{c}\text { Índice de } \\
\text { accountability }\end{array}$ & $\begin{array}{l}\text { Índice de } \\
\text { estrategia }\end{array}$ & \begin{tabular}{|c|} 
Índice de \\
gobierno \\
corporativo
\end{tabular} & $\begin{array}{c}\text { Índice de } \\
\text { compromiso } \\
\text { social }\end{array}$ & $\begin{array}{c}\text { Índice de } \\
\text { impacto } \\
\text { medioambiental }\end{array}$ & Región \\
\hline 1 & BP & 4 & 75,2 & 82,9 & 85,4 & 73,7 & 58,9 & Europa \\
\hline 2 & Barclays & 83 & 68,5 & 81,7 & 60,7 & 43,0 & 88,4 & Europa \\
\hline 3 & ENI & 26 & 67,9 & 75,6 & 57,8 & 50,5 & 87,5 & Europa \\
\hline 4 & HSBC Holdings & 22 & 67,2 & 93,0 & 66,4 & 59,5 & 50,0 & Europa \\
\hline 5 & Vodafone & 95 & 66,3 & 88,1 & 70,9 & 81,9 & 24,6 & Europa \\
\hline 6 & Royal Dutch/Shell & 3 & 66,0 & 81,2 & 78,9 & 68,1 & 35,7 & Europa \\
\hline 7 & Peugeot & 68 & 63,7 & 85,4 & 65,9 & 28,6 & 75,0 & Europa \\
\hline 8 & HBOS & 58 & 62,0 & 76,0 & 71,7 & 56,4 & 43,8 & Europa \\
\hline 9 & Chevron & 7 & 61,6 & 64,2 & 55,2 & 39,5 & 87,5 & América \\
\hline 10 & DaimlerChrysler & 8 & 60,1 & 81,6 & 66,6 & 48,5 & 43,8 & Europa \\
\hline 11 & Tesco & 55 & 60,0 & 65,6 & 62,9 & 49,0 & 62,5 & Europa \\
\hline 12 & BASF & 81 & 59,8 & 69,8 & 58,0 & 46,4 & 65,2 & Europa \\
\hline 13 & General Electric & 11 & 59,1 & 67,9 & 53,9 & 26,1 & 88,4 & América \\
\hline 14 & ABN Amro & 67 & 57,6 & 85,4 & 52,9 & 35,8 & 56,3 & Europa \\
\hline 15 & ING Group & 13 & 56,9 & 78,4 & 59,9 & 50,9 & 38,4 & Europa \\
\hline 16 & E.ON & 53 & 56,5 & 78,0 & 58,1 & 52,6 & 37,5 & Europa \\
\hline 17 & Statoil & 78 & 56,1 & 66,2 & 61,9 & 34,0 & 62,5 & Europa \\
\hline 18 & Total & 10 & 55,1 & 62,8 & 65,7 & 50,0 & 42,0 & Europa \\
\hline 19 & Repsol YPF & 90 & 54,3 & 63,8 & 56,4 & 53,1 & 43,8 & Europa \\
\hline 20 & Électricité-France & 63 & 54,3 & 82,3 & 47,3 & 50,0 & 37,5 & Europa \\
\hline 21 & Marathon Oil & 92 & 54,2 & 52,9 & 45,3 & 31,1 & 87,5 & América \\
\hline 22 & General Motors & 5 & 53,4 & 81,7 & 65,3 & 25,6 & 41,1 & América \\
\hline 23 & Telefónica & 77 & 52,9 & 76,4 & 58,3 & 46,9 & 29,9 & Europa \\
\hline 24 & $\mathrm{HP}$ & 41 & 52,6 & 84,7 & 54,5 & 40,1 & 31,3 & América \\
\hline 25 & Nestlé & 56 & 51,7 & 73,6 & 52,4 & 27,2 & 53,6 & Europa \\
\hline 26 & Carrefour & 32 & 50,1 & 77,7 & 48,9 & 30,2 & 43,8 & Europa \\
\hline 27 & Ford Motor & 12 & 50,0 & 77,7 & 57,1 & 27,6 & 37,5 & Europa \\
\hline 28 & Petróbras & 65 & 49,8 & 63,5 & 46,1 & 45,7 & 43,8 & América \\
\hline 29 & Matsushita & 59 & 49,7 & 57,4 & 39,5 & 27,1 & 75,0 & Asia \\
\hline 30 & Thosiba & 91 & 49,6 & 70,8 & 46,2 & 43,8 & 37,5 & Asia \\
\hline
\end{tabular}

Fuente: Elaboración propia a partir de Accountability (2007) Accountability Rating 2007. London: Accountability \& CSR Network [www.accountabilityrating.com]. 
Cuadro 4: Índice de RSC empresarial promedio por áreas geográficas en 2007

\begin{tabular}{|l|c|c|c|c|c|}
\hline \multicolumn{1}{|c|}{ Empresas } & $\begin{array}{c}\text { Índice de } \\
\text { accountability }\end{array}$ & $\begin{array}{c}\text { Índice de } \\
\text { estrategia }\end{array}$ & $\begin{array}{c}\text { Índice de } \\
\text { gobierno } \\
\text { corporativo }\end{array}$ & $\begin{array}{c}\text { Índice de } \\
\text { compromiso } \\
\text { social }\end{array}$ & $\begin{array}{c}\text { Índice de } \\
\text { impacto } \\
\text { medioambiental }\end{array}$ \\
\hline Europeas (49 empresas) & 46,9 & 65,6 & 45,4 & 33,5 & 43,2 \\
\hline Asiáticas (15 empresas) & 37,3 & 50,5 & 30,6 & 27,0 & 41,3 \\
\hline Americanas (36 empresas) & 30,6 & 37,1 & 30,2 & 14,5 & 40,6 \\
\hline Total empresas G100 (100) & 39,62 & 53,11 & 37,72 & 25,70 & 41,96 \\
\hline
\end{tabular}

Fuente: Accountability (2007) Accountability Rating 2007. London: Accountability \& CSR Network [www.accountabilityrating.com].

Gráfico 3: La información sobre RSC de las empresas listadas en el Dow Jones Stoxx Global 1800

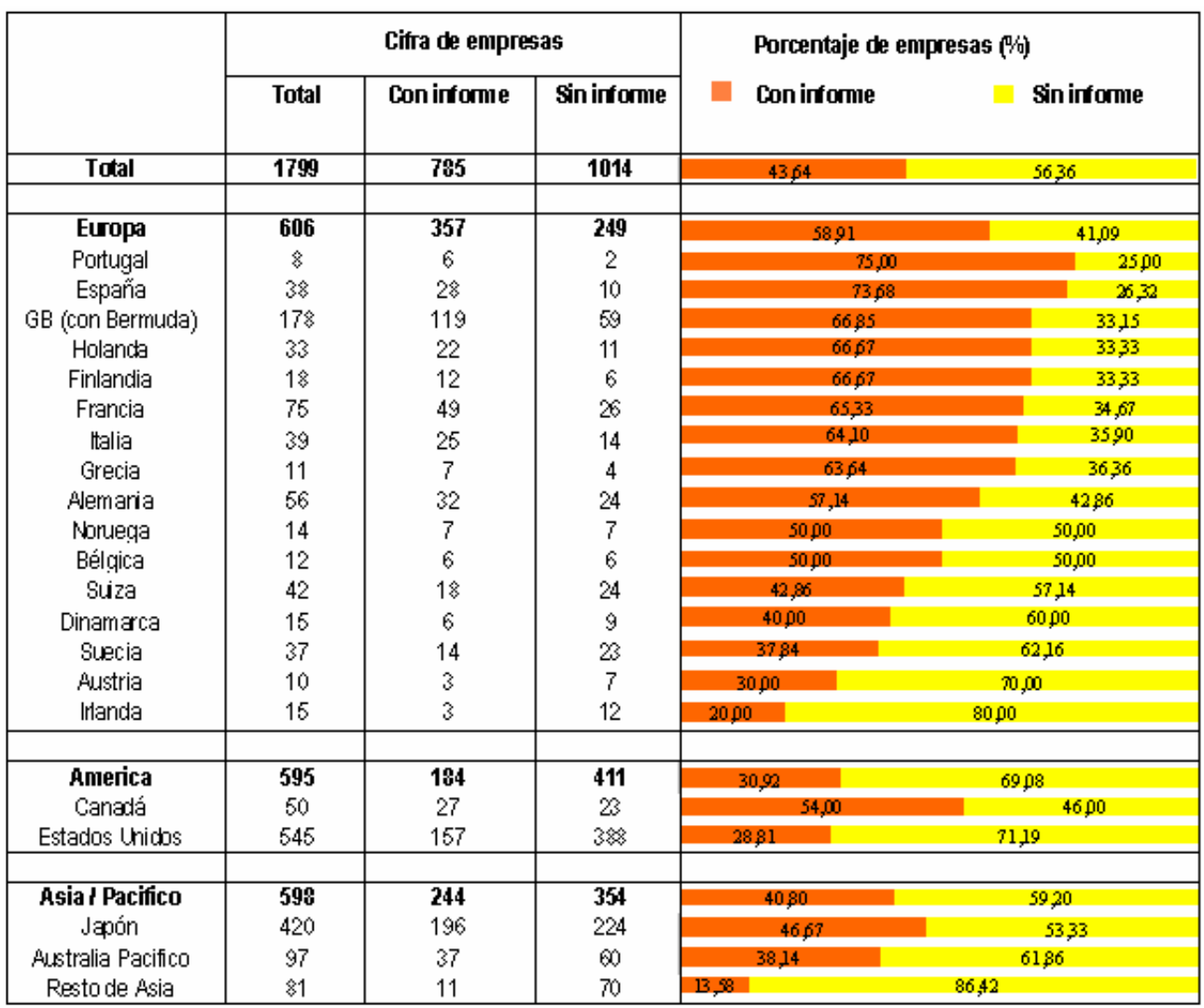

Fuente: Elaboración propia a partir de WestLB (2007) GRI reporting: Aiming to uncover true performance. SIRAN [www.siran.org/pdfs/WestLB_GRI_reporting.pdf]

En el ranking que Accountability elabora anualmente sobre el nivel de RSC de las MNEs incluidas en la lista Fortune Global 100 (G100), las compañías europeas ocupan los primeros puestos (Cuadro 3) y 
tienen valores promedios superiores en los cuatro indicadores (Cuadro 4). Este ranking ordena las empresas de acuerdo al valor de su índice de RSC (o Índice de Accountability), que se construye a partir de cuatro grupos de indicadores sobre: (a) el grado de ajuste de la estrategia de la empresa a los criterios de RSC, (b) la calidad de las prácticas de gobierno corporativo, (c) el compromiso social de la empresa con sus grupos de interés y (d) el impacto ambiental de las actividades de la empresa.

También el análisis de la consultora WestLB (2007) sobre las 1.800 empresas listadas en el índice Dow Jones STOXX Global 1800 -que mantiene una proporción fija de compañías europeas (600), americanas (600) y de Asía/Pacífico (600)- muestra una mayor intensidad en la prácticas de RSC de las MNEs europeas. Según este estudio, cerca del $44 \%$ de ellas (785) elabora memorias no financieras en las que informan de sus actividades en el ámbito medioambiental, social y de gobierno corporativo (environmental, social y governance o ESG). Casi la mitad del total de memorias ESG presentadas (el 46\%), corresponde a empresas europeas, entre las que destacan las del Reino Unido, que elabora el $15 \%$ de las mismas. A pesar de que, en términos absolutos, las empresas del Reino Unido son las que más informes aportan (116), en términos relativos las portuguesas $(75 \%)$ y españolas $(73,68 \%)$ son las que muestran una mayor propensión a comunicar sus compromisos en materia de RSC (Gráfico 3).

Los informes realizados por otras consultoras arrojan resultados similares y matizan algunas conclusiones. Así, EIRIS ha explicado estas diferencias por la necesidad que tienen las empresas europeas de reaccionar a la presión ejercida por instituciones reguladoras y ONGs y atender a una sofisticada demanda de los mercados de consumo y de inversión socialmente responsables (EIRIS 2007). También un estudio de Goldman Sachs (2007) sobre empresas de cinco sectores ha comprobado que en la mayoría de los países europeos, al contrario de lo que ocurre en los países anglosajones (Reino Unido, EEUU, Canadá y Australia), el nivel de cumplimiento de los criterios sociales y medioambientales es superior al de los principios de buen gobierno corporativo (Gráfico 4).

Las diferencias en las prácticas de RSC reflejan el papel que desempeñan las empresas en el marco del entorno institucional en el que operan. Se ha señalado que, en Europa, la RSC está motivada por un consenso social que legitima las expectativas de los grupos de interés respecto al papel y la contribución que las empresas deben hacer a la sociedad. Las normas y valores imperantes en el marco institucional 


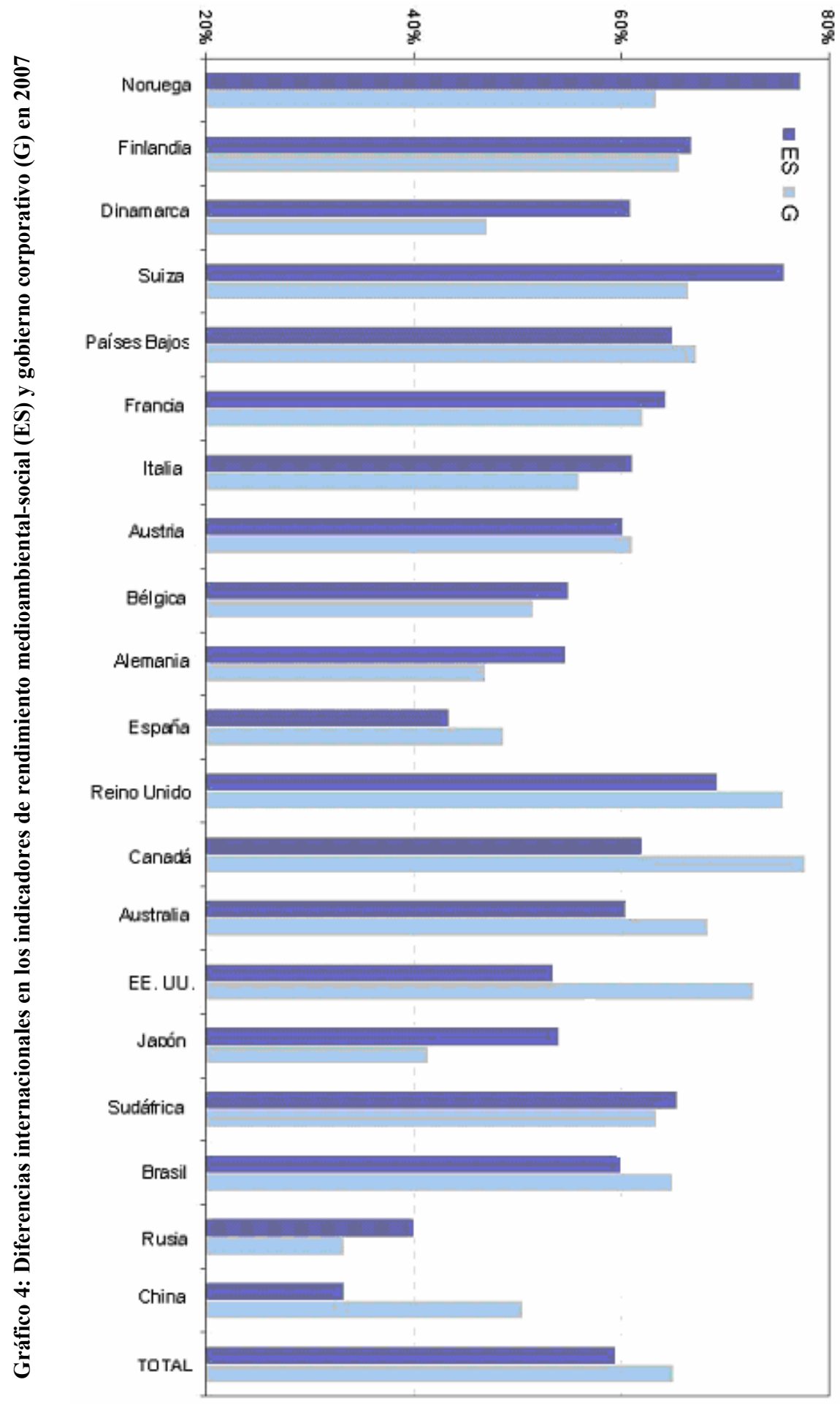

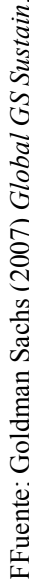

Pecvnia, Monográfico (2008), pp. 33-64 
europeo asignan de forma implícita a las empresas comportamientos socialmente responsables. Por ello la estrategia de RSC de las empresas europeas es menos deliberada que la de las norteamericanas y surge de forma espontánea como reacción al entorno. Por el contrario, los compromisos en RSC de las empresas norteamericanas se manifiestan de forma explícita en sus políticas, programas y estrategias. Las iniciativas de RSC están motivadas por la necesidad de dar respuesta a las expectativas de los principales grupos de interés y son el resultado de una decisión voluntaria, deliberada, con frecuencia estratégica, que busca aprovechar una oportunidad (Matten y Moon 2008).

\subsection{Principios y códigos}

La práctica de la RSC es un proceso que conlleva, por parte de la empresa, la realización de tres actividades: (a) definir los principios y criterios de RSC que se van a adoptar, (b) informar a los grupos de interés de las actividades de RSC realizadas y (c) establecer procedimientos de auditoría externa para certificar ante los grupos de interés el grado de cumplimiento de los criterios de RSC. Las MNEs abordan estas tres actividades de formas muy diferentes.

Respecto al primer aspecto hay que señalar que no existe consenso sobre cuáles son los principios de RSC ni se dispone de un código estándar armonizado a nivel internacional que delimite los comportamientos socialmente responsables. Por el contrario, se ha producido una proliferación de principios y códigos que abordan diferentes aspectos de la RSC, como los relacionados con el gobierno corporativo, las condiciones de empleo, el medio ambiente, la corrupción, etc. Las orientaciones que marcan estos códigos son declaraciones de principios muy generales que admiten una gran discrecionalidad en su aplicación, por lo que las prácticas de RSC a través de las cuales se implementan suelen ser muy variadas.

La gran heterogeneidad de códigos y la flexibilidad de aplicación que permiten sus principios reflejan las diferencias existentes entre los entornos institucionales de los países y las condiciones competitivas de las industrias. Mientras persistan esas diferencias es improbable que se produzca una convergencia en los principios y las prácticas de RSC. Se ha señalado, no obstante, que la mera existencia de estos códigos, algunos de los cuales ha alcanzado una gran difusión (Cuadro 5), está contribuyendo a reducir la dispersión en los modelos de RSC y ha limitado la discrecionalidad de los directivos. 


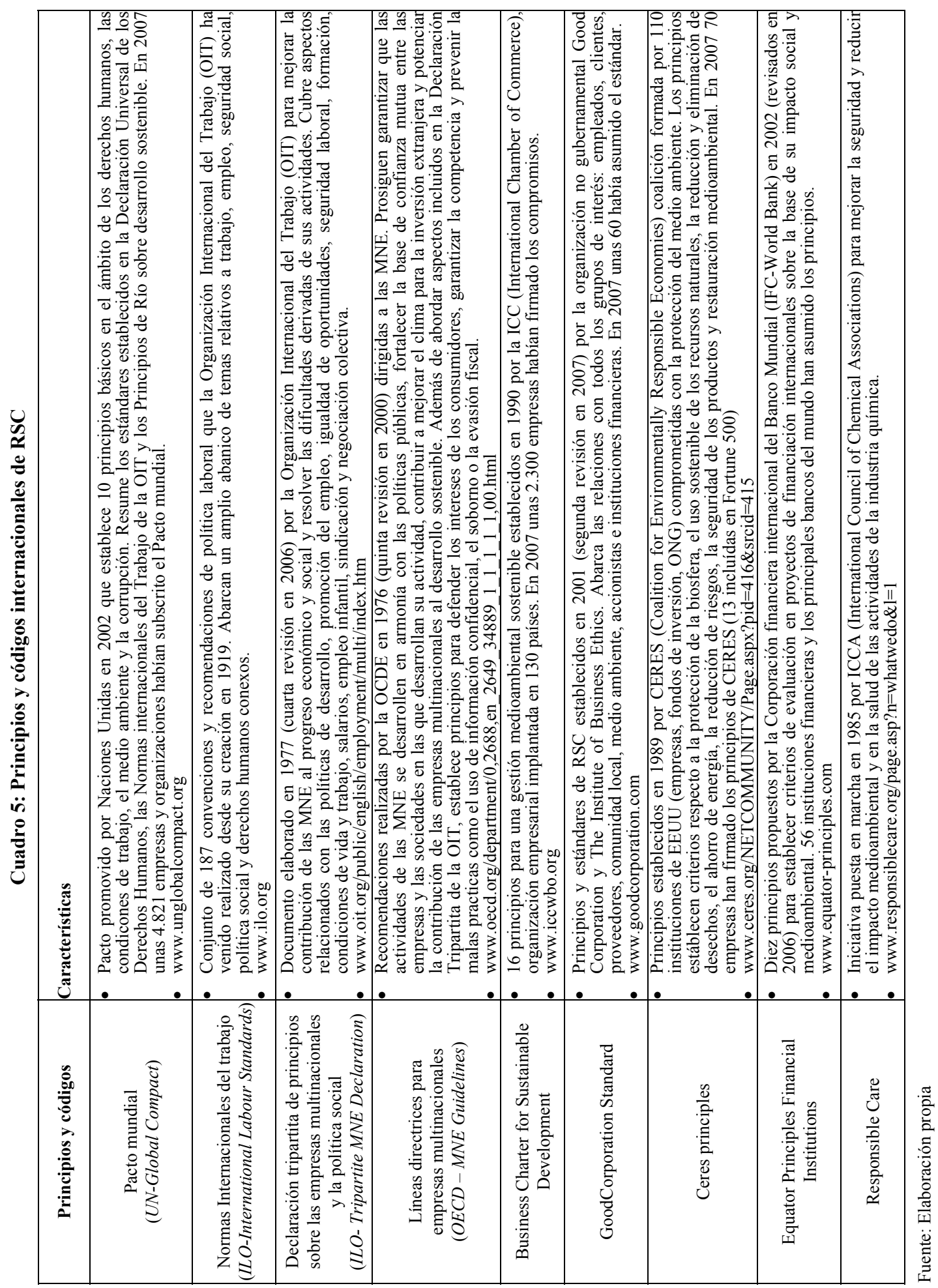

Pecvnia, Monográfico (2008), pp. 33-64 
Hay que tener en cuenta que, al limitar el comportamiento de las empresas, la adopción voluntaria de códigos y estándares internacionales de RSC, puede anular alguna de las fuentes de ventaja competitiva de las MNEs. Así, aunque uno de los objetivos de la estrategia de expansión internacional persigue explotar las oportunidades que ofrecen las diferencias entre los entornos nacionales en materia de regulación corporativa, protección medioambiental o condiciones laborales, las empresas que asuman los códigos de RSC renunciarán a estas fuentes de ventaja y se situarán en una posición de inferioridad respecto a sus competidores.

No obstante, en ciertas circunstancias la autorregulación y el cumplimiento de ciertos códigos de RSC armonizados internacionalmente pueden producir algunos efectos positivos como los que se mencionan a continuación:

- La certificación del cumplimiento de estándares internacionales de gestión medioambiental (como el ISO 14.000) o de responsabilidad social (SA 8000) facilita el comercio internacional al reducir el coste de gestionar la cadena de valor a nivel global.

- El establecimiento de estándares universales reduce la proliferación de normas nacionales, industriales o específicas de ciertos grupos de clientes, las cuales incrementan los costes de las MNEs, que deben adaptar su oferta a sus requerimientos.

- La certificación del cumplimiento de los estándares internacionales por parte de los proveedores reduce el coste de control por parte de las MNEs en la cadena de suministro global.

- Las empresas proveedoras de las MNEs, especialmente las localizadas en países emergentes con bajos niveles de regulación mejorarán la calidad del entorno institucional al adaptarse a los estándares internacionales exigidos por sus clientes.

\subsection{Modelos de informes y normas de acreditación}

La estructura de los informes a través de los cuales las MNEs comunican sus prácticas de RSC a los grupos de interés es muy heterogénea, lo que dificulta el seguimiento y el control de los avances conseguidos por cada empresa y establecer comparaciones entre ellas. No obstante, en los últimos años ha aumentado el número de empresas que ha adaptado la estructura de sus informes sobre RSC a alguno de los modelos propuestos (Cuadro 6). 


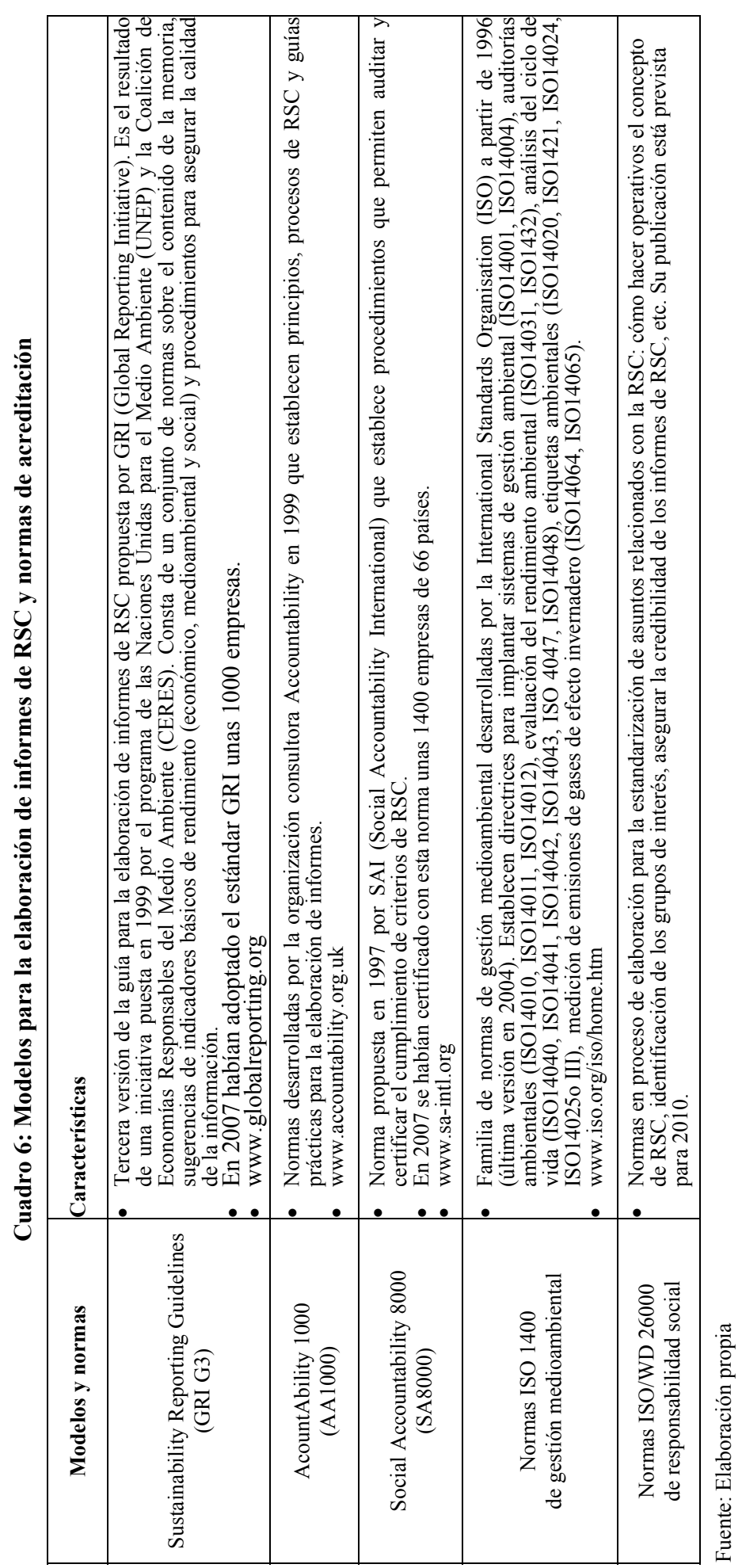

Pecvnia, Monográfico (2008), pp. 33-64 
El Sustainability Reporting Guideline desarrollado por la Foundation Global Reporting Initiative (GRI) es el estándar más difundido entre las MNEs. En la actualidad más de 1.000 empresas y organizaciones de 60 países han adoptado el modelo GRI para la elaboración de los informes RSC, entre las que se encuentran las cinco marcas de mayor valor -Coca-Cola, Microsoft, IBM, General Electric y Nokia- y el $80 \%$ de las quince marcas más valiosas según el ranking elaborado por Interbrand.

Los informes sobre RSC hacen más transparentes a las empresas ante los grupos de interés porque ofrecen: (a) un resumen preciso de los comportamientos RSC que ha tenido la empresa en el pasado y (b) una evaluación del sistema de gestión actual y las actividades de RSC que desarrolla en la actualidad y que, probablemente, determinará su comportamiento en el futuro. Los informes de RSC proporcionan información de base a las auditoras (SAM, EIRIS) y a las agencias de rating para elaborar sus índices de RSC, como el Dow Jones Responsibility Index o FTSGood. Las empresas que consiguen entrar en estos índices demuestran su capacidad para crear valor en el futuro al tiempo que informan a los inversores socialmente responsables de que tienen un nivel de compromiso social y medioambiental elevado.

No obstante, como ha puesto de manifiesto la evaluación realizada por WestLB (2007) acerca de un millar de informes de RSC, su calidad está muy lejos del nivel que ofrecen las memorias financieras. La mayoría de los informes sobre RSC no cumplen los niveles mínimos en cuanto a amplitud de aspectos tratados, calidad de información y posibilidad de establecer comparaciones.

\section{CONCLUSIONES}

Probablemente las prácticas de RSC continuarán difundiéndose internacionalmente a medida que aumente la presión de los grupos de interés. Mientras persista la demanda de comportamientos socialmente responsables, las MNEs y sus directivos continuarán empleando criterios de RSC. Las expectativas de los grupos de interés, que se manifiestan a través del aumento de la presión reguladora y de la modificación de las pautas de la demanda en los mercados, obligarán a las empresas a incorporar progresivamente principios de RSC en sus procedimientos y rutinas de gestión. 
Los factores externos son necesarios para estimular la RSC pero no suficientes. Para crear valor a largo plazo es imprescindible que, al mismo tiempo se mantengan las expectativas sobre la capacidad de la RSC. Si las prácticas de RSC permiten reducir riesgos y acumular intangibles, las empresas las incorporarán en sus estrategias.

Esto plantea una duda sobre el núcleo del concepto de RSC. Si el comportamiento de la empresa es el resultado de la presión de factores externos y se limita a satisfacer las expectativas de los grupos de interés, equilibrando sus objetivos con el objetivo último de seguir creando valor, la RSC no sería el reflejo de sus valores sino que entraría dentro de la racionalidad económica. De esta forma, los criterios de RSC se convierten en el instrumento que permite a las empresas canalizar las preferencias en materia de responsabilidad social de los grupos de interés, lo que cuestionaría la idea comúnmente aceptada de que los comportamientos socialmente responsables son aquéllos que van más allá del cumplimiento de los criterios legales y económicos.

Lo mismo se podría argumentar respecto a las oportunidades que presenta la adopción de prácticas de RSC en el interior de la empresa. La capacidad de la RSC para crear valor a largo plazo reduciendo riesgos y acumulando activos intangibles justifica su empleo bajo estrictos criterios de racionalidad y eficiencia.

Por último, señalar que la adopción e implantación de prácticas de RSC presenta problemas aún no resueltos. Unos afectan directamente a la dirección y organización interna de la empresa y su solución pasa por el desarrollo de nuevos sistemas de información que permitan incorporar los criterios de RSC en la toma de decisiones. Otros escapan del ámbito interno de la empresa y están relacionados con la generalización del empleo de mecanismos externos que permitan auditar el grado de cumplimiento de los criterios de RSC.

\section{BIBLIOGRAFÍA}

ACCOUNTABILITY (2007) Accountability Rating 2007. Accountability \& CSR Network [www.accountabilityrating.com].

- (2007) The State of Responsible Competitiveness 2007. Accountability [www.accountability21.net]. 
BAGNOLI, M. and S.G. WATTS, (2003) "Selling to Socially Responsible Consumers: Competition and the Private Provision of Public Goods", Journal of Economics and Management Strategy, 12 (3), pp. 419-445.

BARON, D.P. (2001) "Private Politics, Corporate Social Responsibility, and Integrated Strategy", Journal of Economics and Management Strategy, 10 (1), pp. 7-45.

BÉTHOUX, E.; C. DIDRY and A. MIAS (2007) "What Codes of Conduct Tell Us: Corporate Social Responsibility and the Nature of the Multinational Corporation", Corporate Governance: An International Review, 15 (1), pp. 77-90.

BONDY, K.; D. MATTEN and J. MOON (2008) "MNC Codes of Conduct: Governance Tools for CSR?", Corporate Governance: An International Review, forthcoming 2008.

CRANE, A. (2000) "Corporate greening as amoralization", Organization Studies, 21 (4), pp. 673-696.

DAVIS, I. (2005) "The biggest contract", The Economist, 26 Mayo, p. 87.

DELOITTE (2007) Corporate Responsibility reporting reaches all time high [www.deloitte.com/dtt/press_release/0,1014,sid\%253D2833\%2526cid\% 253D182646,00.htlm].

EIRIS (2007) The state of responsible business: Global corporate response to environmental, social and governance (ESG) challenges. Ethical Investment Research Services [www.eiris.org/files/research\%20publ ications/stateofrespbusinesssep07.pdf].

FERNÁNDEZ GAGO, R. (2005) Administración de la responsabilidad social corporativa. Madrid: Thomson.

GHOSHAL, S. (2005) "Bad management theories are destroying good management practices", Academy of Management Learning \& Education, 4 (1), pp. 75-91.

Goldman Sachs Global InVestment Research (2007) Global GS Sustain. The Goldman Sachs Group, Inc. [http://www2.goldmansachs.com].

GOND, J.P.; G. PALAZZO and K. BASU (2007) "Investigating Instrumental CSR through the Mafia Metaphor". International Centre for Corporate Social Responsibility (ICCSR), Research Paper Series No. 48-2007. Nottingham, UK: Nottingham University Business School.

JensEn, M.C. (2001) "Value maximization, Stakeholder Theory, and the corporate objective function", Journal of Applied Corporate Finance, 11 (3), pp. 8-21. 
KING, A.A. and M.L. LeNOX (2000) "Industry Self-Regulation Without Sanctions: The Chemical Industry's Responsible Care Program", Academy of Management Journal, 43 (4), pp. 698-716.

KolK, A.; R. VAN TULDER and B. WeSTDIJK (2006) "Poverty alleviation as business strategy? Evaluating commitments of frontrunner Multinational Corporations", World Development, 34 (5), pp. 789-801.

KPMG (2002) KPMG International survey of corporate sustainability reporting 2002. KPMG [www.kpmg.nl].

- (2005) KPMG International survey of corporate responsibility reporting 2005. KPMG [www.kpmg.nl].

LUO, Y. (2005) "Corporate governance and accountability in multinational enterprises: Concepts and agenda", Journal of International Management, 11 (1), pp. 1-18.

LYON, T.P. and J.W. MAXWELL (2006) "Greenwash: Corporate Environmental Disclosure Ander Threat of Audit", Working Paper, Stephen M. Ross School of Business, University of Michigan, EEUU.

MacGillivray, A.; P. Begley and S. ZAdek eds. (2007) The State of Responsible Competitiveness 2007. Londres: AccuntAbility, [www.acc ountability21.net].

MAIGNAN, I. and D.A. RALSTON (2002) "Corporate Social Responsibility in Europe and the U.S.: Insights from Businesses' Self-Presentations", Journal of International Business Studies, 33 (3), pp. 497-514.

MARGOLIS, J.D. and P. WALSH (2003) "Misery loves companies: Rethinking social initiatives by business", Administrative Science Quarterly, 48 (2), pp. 268-305.

MATTEN, D. and J. MOON (2008) "Implicit and Explicit CSR A conceptual framework for a comparative understanding of corporate social responsibility", Academy of Management Review, 33 (2), pp. 404-424.

MAXWELL, J.W.; T.P. LYON and S.C. HACKETT (2000) "Self Regulation and Social Welfare: The Political Economy of Corporate Environmentalism", Journal of Law and Economics, 43 (2), pp. 583-618.

MCKINSEY\&COMPANY (2007) Shaping the new rules of competition UN global compact participant mirror. McKinsey y Company [www.unglobalcomp act.org/docs/summit2007/mckinsey_embargoed_until020707.pdf].

MCWILliAmS, A. and D. SIEGEL (2001) "Corporate Social Responsibility: A Theory of the Firm Perspective", Academy of Management Review, 26 (1), pp. 117-127. 
MCWILliams, A.; D. SIEGEL and P. WRIGHT (2006) "Corporate Social Responsibility: International Perspectives", Journal of Business Strategies, 23 (1), pp. 1-8.

MCWILliams, A.; D. Siegel and P.M. WRIGHT (2006) "Corporate Social Responsibility: Strategic Implications", Journal of Management Studies, 43 (1), pp. 1-18.

Nieto, M. (2005) "La difusión de la RSC en la empresa española", Economistas, 106, pp. 32-45.

ORLITZKY, M.; F.L. SCHMIDT and S.L. RYNES (2003) "Corporate social and financial performance", Organization Studies, 24 (3), pp. 403-433.

PoRTER, M.E. and M.R. KRAMER (2002) "The competitive advantage of corporate philanthropy", Harvard Business Review, Vol. 80, No. 12, pp. 56-68.

PRAHALAD, C.K. (2005) La fortuna en la base de la pirámide: Como crear una vida digna y aumentar las opciones mediante el mercado. Barcelona: Granica.

PutNAM, R. Ed. (2003) El declive del capital social. Barcelona: Galaxia Gutemberg-Circulo de Lectores.

SETHI, S.P. (1990) "An analytical framework for making cross cultural comparisons of business responses to social pressures: The case of the United States and Japan". L.E. PRESTON (ed.) International and Comparative Corporation and Society Research. Greenwich, CT: JAI Press, pp. 29-56.

SHEARER, T. (2002) "Ethics and Accountability: From the for-itself to the forthe-other", Accounting, Organizations and Society, 27 (6), pp. 541-573.

SPENCE, M. (2002) "Signalling in retrospect and the informational structure of markets", American Economic Review, 92 (3), pp. 434-459.

STIGLITZ, J. (2006) Cómo hacer que funcione la globalización. Madrid: Taurus.

WESTLB (2007) GRI reporting: Aiming to uncover true performance. Social Investment Research Analyst Network [www.siran.org/pdfs/WestLB_G RI_reporting.pdf].

WILLIAMSON, O. (1993) "Calculativeness, trust and economic organization", Journal of Law and Economics, 36 (1), pp. 453-486. 